\title{
Determinants and patterns of service utilization and recourse to professionals for mental health reasons
}

Marie-Josée Fleury ${ }^{1,2^{*}}$, Guy Grenier ${ }^{2}$, Jean-Marie Bamvita ${ }^{2}$ and Jean Caron ${ }^{1}$

\begin{abstract}
Background: This study has a dual purpose: 1) identify determinants of healthcare service utilization for mental health reasons (MHR) in a Canadian (Montreal) catchment area; 2) determine the patterns of recourse to healthcare professionals in terms of frequency of visits and type of professionals consulted, and as it relates to the most prevalent mental disorders (MD) and psychological distress.

Methods: Data was collected from a random sample of 1,823 individuals interviewed after a two-year follow-up period. A regression analysis was performed to identify variables associated with service utilization and complementary analyses were carried out to better understand participants' patterns of healthcare service utilization in relation to the most prevalent MD.

Results: Among 243 individuals diagnosed with a MD in the 12 months preceding an interview, 113 (46.5\%) reported having used healthcare services for MHR. Determinants of service utilization were emotional and legal problems, number of MD, higher personal income, lower quality of life, inability of individuals to influence events occurring in their neighborhood, female gender and, marginally, lack of alcohol dependence in the past 12 months. Emotional problems were the most significant determinant of healthcare service utilization. Frequent visits with healthcare professionals were more likely associated with major depression and number of MD with or without dependence to alcohol or drugs. People suffering from major depression, psychological distress and social phobia were more likely to consult different professionals, while individuals with panic disorders relied on their family physician only. Concerning social phobia, panic disorders and psychological distress, more frequent visits with professionals did not translate into involvement of a higher number of professionals or vice-versa.

Conclusions: This study demonstrates the impact of emotional problems, neighborhood characteristics and legal problems in healthcare service utilization for MHR. Interventions based on inter-professional collaboration could be prioritized to increase the ability of healthcare services to take care especially of individuals suffering from social phobia, panic disorders and psychological distress. Others actions that could be prioritized are training of family physicians in the treatment of MD, use of psychiatric consultants, internet outreach, and reimbursement of psychological consultations for individuals with low income.
\end{abstract}

Keywords: Service utilization, Mental health, Determinants, Professionals

\footnotetext{
* Correspondence: flemar@douglas.mcgill.ca

'Department of Psychiatry, McGill University, Douglas Hospital Research

Centre, 6875 LaSalle Blvd, Montreal, Quebec H4H 1R3, Canada

${ }^{2}$ Douglas Hospital Research Centre, Montreal, Quebec H4H 1R3, Canada
} 


\section{Background}

Epidemiological studies reveal that only a minority of individuals suffering from mental disorders use healthcare services [1-6]. For example, only $26 \%$ of Europeans suffering from a mental disorder in a 12-month period had consulted a professional according to a meta-analysis [7]. In Canada, the ratio of individuals using healthcare services for mental health reasons (MHR) was only 39\% according to the 2002 Canadian Community Health Survey of Mental Health and Well-Being (CCHS 1.2) [8]. These findings underscore the need to find better ways to identify potential barriers to healthcare services.

Andersen's behavioural model is the most common tool used for identifying determinants of healthcare service utilization [9]. In this model, variables are divided into predisposing, enabling and needs-related factors. Predisposing factors are individual characteristics that exist prior to the illness. Gender [10-12], age [11,13], marital status $[4,14,15]$, and education are the chief predisposing factors associated with healthcare service utilization for MHR. Enabling factors are aspects that influence care delivery. The primary predisposing factors related to healthcare service utilization for MHR are income $[16,17]$, insurance coverage $[16,18]$, place of residence [19] and social support [20,21]. Needs-related factors include diagnosis, number and severity of mental disorders, as well as self-perception of mental and physical health $[22,23]$. According to the literature, needs are the strongest factors impacting healthcare service utilization $[9,24,25]$. Specific diagnoses tend to lead to much higher service utilization: schizophrenia [13], major depression [16], anxiety disorders [13] and cooccurring mental and substance-use disorders [24]. Duration of mental disorder [24], severity of symptoms [15], psychological distress [26] and poor physical health [23] are other needs-related factors that lead to higher service utilization.

Few studies have investigated determinants related to the types of professionals consulted [27-30]. According to a cross-sectional survey across six Europeans countries, people who are 49 or over and have less education and lower income tend to seek the services of their family physician rather than those of mental health providers [30]. Retired or unemployed individuals with less education and under psychiatric medication are more likely to consult psychiatrists only, while single persons tend to seek the services of other professionals only [29]. Studies have shown that individuals with major depression or mood disorders tend to rely on their family physician [30,31], while anxiety disorder sufferers are much more likely to call on psychiatrists and psychologists [32]. Persons with co-occurring mental health and substance-use disorders call on a broad range of professionals [31].
Previous studies have highlighted the key determinants of healthcare service utilization. Several variables, however, such as religious beliefs, neighborhood/geospatial information, dealings with the justice system, impulsivity, aggressive behaviour and violence have received little or no attention [33]. Few studies have compared the frequency of visits and type of professionals consulted in relation with various mental disorders. Do some diagnoses result in treatment being provided by one professional only or several types of professionals? If one seeks the services of a higher number of professionals, does that translate into more frequent visits?

This study has a dual purpose: 1) identify determinants of healthcare service utilization for mental health reasons in a Canadian (Montreal) catchment area; 2) determine the pattern of recourse to healthcare professionals in terms of frequency of visits and type of professionals consulted, and as it relates to the most prevalent mental disorders and psychological distress.

\section{Methods \\ Study design and setting}

This article is based on cross-sectional analyses from a broader longitudinal study in an epidemiological catchment area in Montreal, Canada's second-largest city with a population of 3.6 million. The catchment area had a population of 269,720 spread over four neighborhoods ranging in population from 29,680 to 72,420 . A third of the residents had low income (versus $23 \%$ in the province of Quebec and 35\% in Montreal). In two neighbourhoods, the proportion of low income earners was close to half. Healthcare services are delivered primarily by a psychiatric hospital delivering specialized care (secondand third-line services) and two health and social service centers (created through the merger of a general hospital, community local service centers and nursing homes) offering both primary and specialized healthcare. Primary care is provided also by about 40 medical clinics and a similar number of private psychologists, along with 16 mental community-based agencies [34].

\section{Selection criteria and survey sample}

To be included in the study, participants had to be aged between 15 and 65, reside in the catchment area, approve to participate after clear explanation of the study and fill in a consent form. For those aged 15 to 17, parents had to give authorization before the interview. Participants were selected so as to obtain a representative sample in terms of age, gender and socio-economic status, i.e. representative of varying degrees of educational attainment within the area, as well as geographically, i.e. recruiting participants from all areas of the territory proportionally to population density. 
Data were prospectively collected from June 2007 to December 2010. At baseline (T1: June 2007 to December 2008), 2,434 individuals took part in the survey, for a co-operation rate of $48.7 \%$. All participants were contacted for a second interview (T2) between June 2009 and December 2010. Only 611 were lost or excluded at follow-up because they had moved out of the catchment area or had died, and 1,823 responded to T2, for a retention rate of $74.9 \%$. The attrition rate at T2 $(25.1 \%)$ included only 138 refusals to participate (5.7\%); 230 individuals $(9.4 \%)$ had moved outside the catchment area, 231 (9.4\%) were not reachable, and $12(0.5 \%)$ had died. This attrition rate after two years was better than that observed in American epidemiological catchment areas after one year (20.4\%, including $12.6 \%$ refusals) [35]. The attrition rates were higher among youths, singles, the less-educated, low income earners and those with substance dependence. This is similar to what was observed in other epidemiological catchment areas studies [35-37]. Douglas Mental health Institute Research Ethics Board Committee approved the research. The sampling strategy and data collection (especially at T1) are described in detail in related publications $[33,34,38]$.

\section{Variables and measurement instruments}

The dependent variable was "healthcare utilization in the 12 months prior to the interview at T2". Independent variables were measured at T2 and organized according to Andersen's behavioural model of healthcare service utilization, comprising predisposing determinants (age, gender, education, self-perception of physical health, self-perception of mental health, importance attributed to spirituality, number of children in the household, and problems with the law in past 12 months), enabling factors (household income, personal income, quality of life, neighbourhood characteristics, and social support) and needs-related factors (type and number of mental disorders, emotional problems, harm caused by violence, aggressive behavior [all of those in the past 12 months], and psychological distress). Table 1 displays the instruments used to measure the variables.

\section{Analyses}

Analyses entailed descriptive analyses (frequency distribution, mean values and standard deviation), bivariate analyses (comparison analyses using chi-square tests between participants who used healthcare services and those

Table 1 Variables assessed in the study

\begin{tabular}{|c|c|c|}
\hline Variables & & Measuring instruments \\
\hline \multirow[t]{8}{*}{ Predisposing factors } & Age & \multirow{8}{*}{$\begin{array}{l}\text { Canadian Community Health Survey of Mental Health } \\
\text { and Well-Being CCHS 1.2 [39] }\end{array}$} \\
\hline & Gender & \\
\hline & Education & \\
\hline & Self-perception of physical health & \\
\hline & Self-perception of mental health & \\
\hline & Importance attributed to spirituality & \\
\hline & Number of children in the household & \\
\hline & Problems with the law in past 12 months & \\
\hline \multirow[t]{8}{*}{ Enabling factors } & Household income & \multirow[t]{2}{*}{ CCHS 1.2 [39] } \\
\hline & Personal income & \\
\hline & Quality of life & Satisfaction with Life Domains Scale [40] \\
\hline & \multirow[t]{3}{*}{ Neighborhood characteristics } & Physical Conditions of the Neighbourhood [41] \\
\hline & & Neighbourhood Disorder Scale [42] \\
\hline & & Community Participation Scale [43] \\
\hline & \multirow[t]{2}{*}{ Social support } & Resident Disempowerment Scale [44] \\
\hline & & Social Provisions Scale (SPS) [45] \\
\hline \multirow[t]{6}{*}{ Needs-related factors } & $\begin{array}{l}\text { Mental disorders (MD) in past } 12 \text { months (major depression, } \\
\text { mania, panic disorder, social phobia, agoraphobia, post-traumatic } \\
\text { stress disorder, alcohol dependence, drug dependence) }\end{array}$ & \multirow[t]{2}{*}{ Composite International Diagnostic Interview (CIDI), [39] } \\
\hline & Number of MD in past 12 months & \\
\hline & Emotional problems in past 12 months & CCHS 1.2 [39] \\
\hline & Victims of violence in past 12 months & CCHS 1.2 [39] \\
\hline & Aggressive behaviors in past 12 months & $\begin{array}{l}\text { Modified Observed Aggression Scale (MOAS) for } \\
\text { aggressive behaviours [46] }\end{array}$ \\
\hline & Psychological distress & K-10 psychological distress scale [47] \\
\hline
\end{tabular}


who did not), and multiple logistic regression. The regression analysis identified variables associated with service utilization for MHR at T2. The first step was to identify the variables that, based on the Andersen factors, had a significant bivariate relationship $(\mathrm{p}<0.10)$ with service utilization. These variables were then entered into a multivariable logistic regression analysis. A two-tailed $\mathrm{P}<0.05$ was considered statistically significant for an independent association between the outcome and a given independent variable. The model goodness-of-fit was assessed using the Hosmer-Lemeshow test while the total variance explained by the model was calculated using Nagelkerke $\mathrm{R}^{2}$.

Two sets of complementary analyses were carried out to gain a better understanding of participants' patterns of healthcare service utilization as they related to the most prevalent mental disorders. The first set, which considered participants who had used healthcare services at T2, entailed distribution of mean values along with standard deviations of frequency of visits with healthcare professionals in connection with major depression, panic disorder, social phobia, psychological distress and number of mental disorders, including or excluding dependence to alcohol and drugs. Comparison tests were carried out to determine those associations using the ANOVA t-test. The second set of analyses consisted in frequency distribution of visits with healthcare professionals at T2 in connection with major depression, panic disorder, social phobia and psychological distress. Comparison tests were carried out using Pearson's chi-square test and Fisher's exact test to assess the link between mental disorders and recourse to healthcare professionals.

\section{Results}

From a total of 1,823 participants who responded to the questionnaire at T2, 243 individuals (13.3\%) had at least one mental disorder and were selected for subsequent analyses. The proportion of females was twice that of males (Table 2). The majority (68\%) reported having more than high-school education. The majority felt that their physical (55\%) and mental health (54\%) was excellent or very good. The most prevalent mental illness was major depression. Only $47 \%$ of individuals having mental disorders had used healthcare services for mental reasons in the 12 months before the interview.

Bivariate analyses between those who used healthcare services for MHR and those who did not showed that the former were mostly females (Table 2). They were more educated and felt that their mental health was excellent or very good, although they had legal problems (predisposing factors). They had also on average a higher personal income (self-reported from the questionnaire of the CCHS 1.2, Table 1), a stronger perception of their inability to affect neighborhood conditions According to the Resident Disempowerment scale and a lower quality of life (enabling factors). They had more mental disorders and suffered mostly from major depression, alcohol dependence and, marginally, agoraphobia. They also had higher psychological distress (according to the K-10 psychological distress scale), and more emotional and mental-health-related problems (needs-related factors) (Table 2).

The variables associated with healthcare service utilization for MHR in bivariate analyses were used to create the multiple logistic regression model assessing variables independently linked to healthcare utilization displayed in Table 3. Eight variables were retained in this model. Half were positively associated (legal problems, emotional problems and number of mental disorders and personal income). The other half were negatively associated (gender, quality of life score, perceived inability to influence neighbourhood conditions and, marginally, alcohol dependence in the past 12 months). The two largest determinants of healthcare utilization were emotional problems (OR: 8.672) and legal problems (OR: 6.976). As shown by the Hosmer-Lemeshow Statistic, this model has an acceptable goodness-of-fit and explains $37 \%$ of the total variance.

A total of 467 participants (with or without a mental disorder diagnosis) visited healthcare professionals for MHR. Table 4 shows their pattern of recourse to healthcare professionals for the most prevalent mental disorders and psychological distress. Almost 30\% of participants saw a family physician, psychiatrist, psychologist and other professionals (nurse, social worker, addiction counsellor, etc.) together, while $25 \%$ called on a family physician, a psychiatrist and a psychologist. When comparing participants with and without major depression, we found that the former were more likely to consult all types of healthcare professionals, alone or in combination. Compared to participants without psychological distress, those who did have this problem more often sought help from all types of health professionals, although they were unlikely to request the services of other professionals only. Compared to participants without social phobia, those who suffered from this anxiety disorder tended to see a psychologist or other professional only; a psychologist with a family physician or psychiatrist; a psychologist, family physician and psychiatrist combined, or all three along with another professional. Finally, participants with panic disorder (as compared to those without) tended to rely on their family physician only.

Table 5 displays the frequency of visits for each professional in connection with major depression, panic disorder, social phobia, psychological distress and number of mental disorders, including or excluding dependence to alcohol and drugs. Compared to participants without major depression, those who suffered from this illness had much more frequent visits with all types of professionals, 
Table 2 Descriptive characteristics of participants at baseline (T1) and comparison analyses according to healthcare service utilization ( $\mathrm{N}=243$ )

\begin{tabular}{|c|c|c|c|c|c|c|}
\hline & & & 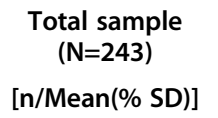 & $\begin{array}{c}\begin{array}{c}\text { No utilization } \\
(n=130)\end{array} \\
{[n / \text { Mean(\% SD)] }}\end{array}$ & $\begin{array}{c}\begin{array}{c}\text { Utilization } \\
(n=113)\end{array} \\
\text { [n/Mean(\% SD)] }\end{array}$ & $\begin{array}{c}\text { P value } \\
\text { (chi-square test) }\end{array}$ \\
\hline \multirow[t]{14}{*}{ Predisposing factors } & \multicolumn{2}{|l|}{ Age [Mean(SD)] } & $43.3(12.8)$ & $42.2(13.6)$ & $44.5(11.8)$ & .165 \\
\hline & \multirow[t]{2}{*}{ Gender $[n(\%)]$} & Female & $160(65.8)$ & $73(56.2)$ & $87(77.0)$ & .001 \\
\hline & & Male & $83(34.2)$ & $57(43.8)$ & $26(23.0)$ & \\
\hline & \multirow[t]{2}{*}{ Education [n(\%)] } & High school or less & $78(32.1)$ & $53(40.8)$ & $25(22.1)$ & .002 \\
\hline & & Beyond high school & $165(67.9)$ & $77(59.2)$ & $88(77.9)$ & \\
\hline & \multirow[t]{3}{*}{ Self-perception of physical health [n(\%)] } & Poor or fair & $42(17.3)$ & $25(19.2)$ & $17(15.0)$ & .073 \\
\hline & & Good & $68(28.0)$ & $42(32.3)$ & $26(23.0)$ & \\
\hline & & Excellent or very good & $133(54.7)$ & $63(48.5)$ & $70(61.9)$ & \\
\hline & \multirow[t]{3}{*}{ Self-perception of mental health [n(\%)] } & Poor or fair & $37(15.2)$ & $28(21.5)$ & $9(8.0)$ & 0.001 \\
\hline & & Good & $76(31.3)$ & $43(33.1)$ & $33(29.2)$ & \\
\hline & & Excellent or very good & $130(53.5)$ & $59(45.4)$ & $71(62.8)$ & \\
\hline & \multicolumn{2}{|l|}{ Importance attributed to spirituality [n(\%)] } & $141(58.0)$ & $75(57.7)$ & $66(58.4)$ & .910 \\
\hline & \multicolumn{2}{|l|}{ Number of children in the household [Mean(SD)] } & $0.5(0.9)$ & $0.5(1.0)$ & $0.5(0.9)$ & .740 \\
\hline & \multicolumn{2}{|l|}{ Problems with the law in past 12 months } & $11(4.5)$ & $3(2.3)$ & $8(7.1)$ & .090 \\
\hline \multirow[t]{8}{*}{ Enabling factors } & \multicolumn{2}{|l|}{ Household income [Mean(SD)] } & $49552.1(41246.8)$ & $46105.7(32878.9)$ & $53517.0(49002.7)$ & .167 \\
\hline & \multicolumn{2}{|l|}{ Personal income [Mean(SD)] } & $28215.1(21927.0)$ & $24845.7(17118.1)$ & $32091.4(25942.6)$ & .014 \\
\hline & \multicolumn{2}{|l|}{ Quality of life score [Mean(SD)] } & $95.2(17.7)$ & $97.4(16.6)$ & $92.7(18.6)$ & .040 \\
\hline & \multirow[t]{4}{*}{ Neighbourhood characteristics scores } & Neighborhood physical condition [Mean(SD)] & $43.6(12.3)$ & $42.5(12.2)$ & $44.8(12.4)$ & .136 \\
\hline & & Neighborhood disorder [Mean(SD)] & $3.9(1.4)$ & $3.9(1.4)$ & $3.9(1.4)$ & .921 \\
\hline & & Community involvement [Mean(SD)] & $0.8(1.0)$ & $0.7(1.1)$ & $0.9(1.0)$ & .173 \\
\hline & & Resident disempowerment [Mean(SD)] & $12.8(6.2)$ & $13.6(6.2)$ & $11.9(6.0)$ & .036 \\
\hline & \multicolumn{2}{|l|}{ Social support score [Mean(SD)] } & $77.8(10.8)$ & $78.3(11.0)$ & $77.2(10.5)$ & .454 \\
\hline \multirow[t]{8}{*}{ Needs } & \multirow[t]{8}{*}{ Mental disorders (MD) in past 12 months } & Major depression [n(\%)] & $147(60.5)$ & $66(50.8)$ & $81(71.7)$ & .001 \\
\hline & & Mania $[n(\%)]$ & $13(5.3)$ & $6(4.6)$ & $7(6.2)$ & .587 \\
\hline & & Panic disorder [n(\%)] & $17(7.0)$ & $7(5.4)$ & $10(8.8)$ & .296 \\
\hline & & Social phobia [n(\%)] & $41(16.9)$ & $21(16.2)$ & $20(17.7)$ & .748 \\
\hline & & Agoraphobia [n(\%)] & $7(2.9)$ & $1(0.8)$ & $6(5.3)$ & .069 \\
\hline & & Alcohol dependence $[n(\%)]$ & $44(18.1)$ & $30(23.1)$ & $14(12.4)$ & .033 \\
\hline & & Drug dependence [n(\%)] & $28(11.5)$ & $18(13.8)$ & $10(8.8)$ & .227 \\
\hline & & Post-traumatic stress disorder [n(\%)] & $18(7.4)$ & $8(6.2)$ & $10(8.8)$ & .426 \\
\hline
\end{tabular}


Table 2 Descriptive characteristics of participants at baseline (T1) and comparison analyses according to healthcare service utilization ( $\mathbf{N}=\mathbf{2 4 3}$ ) (Continued)

\begin{tabular}{|c|c|c|c|c|}
\hline Number of MD in past 12 months [Mean(SD)] & $1.3(0.6)$ & $1.2(0.5)$ & $1.4(0.8)$ & .025 \\
\hline Emotional problems in past 12 months [n(\%)] & $187(77.0)$ & $80(61.5)$ & $107(94.7)$ & $<.001$ \\
\hline Problems related to mental health in past 12 months [n(\%)] & $133(54.7)$ & $42(32.3)$ & $91(80.5)$ & $<.001$ \\
\hline Victim of violence in past 12 months [n(\%)] & $25(10.3)$ & $13(10.0)$ & $12(10.6)$ & .874 \\
\hline Aggressive behaviours in past 12 months [n(\%)] & $39(16.0)$ & $25(19.2)$ & $14(12.4)$ & .150 \\
\hline Psychological distress score [Mean(SD)] & $15.3(7.5)$ & $14.4(7.2)$ & $16.5(7.8)$ & .030 \\
\hline
\end{tabular}


Table 3 Variables independently associated with healthcare service utilization among participants with meantl disorders (MD) and/or psychological distress after 18 months follow-up: multiple logistic regression analysis (T2) $(\mathrm{N}=\mathbf{2 4 3})$

\begin{tabular}{|c|c|c|c|c|c|c|c|c|}
\hline & \multirow[t]{2}{*}{ B } & \multirow[t]{2}{*}{ SE } & \multirow[t]{2}{*}{ Wald } & \multirow[t]{2}{*}{ df } & \multirow[t]{2}{*}{$\mathbf{P}$} & \multirow[t]{2}{*}{ OR } & \multicolumn{2}{|c|}{$95 \% \mathrm{Cl}$} \\
\hline & & & & & & & LB & UB \\
\hline Gender (male) & -.945 & .342 & 7.618 & 1 & .006 & .389 & .199 & .760 \\
\hline Legal problems in past 12 months & 1.943 & .902 & 4.633 & 1 & .031 & 6.976 & 1.190 & 40.909 \\
\hline Alcohol dependence in past 12 past months & -.950 & .488 & 3.797 & 1 & .051 & .387 & .149 & 1.006 \\
\hline Emotional problems in past 12 months & 2.160 & .455 & 22.535 & 1 & $<.001$ & 8.672 & 3.555 & 21.157 \\
\hline Number of mental disorders in past 12 months & .605 & .273 & 4.900 & 1 & .027 & 1.832 & 1.072 & 3.130 \\
\hline Personal income & .000 & .000 & 8.411 & 1 & .004 & 1.000 & 1.000 & 1.000 \\
\hline Quality of life score & -.023 & .006 & 16.925 & 1 & $<.001$ & .978 & .967 & .988 \\
\hline Perceived inability to influence neighbourhood conditions & -.062 & .024 & 6.912 & 1 & .009 & .940 & .897 & .984 \\
\hline
\end{tabular}

except those classified as "other" (social worker, nurses, etc.) alone. Participants with a higher number of mental disorders, including or excluding dependence to alcohol and drugs, visited much more often with all types of professionals, except psychiatrists or other professionals alone. Compared to participants without panic disorder, those suffering from this condition had much more frequent visits with their family physician only, a psychologist only, a psychologist and family physician, a psychiatrist and family physician, a psychiatrist and psychologist or all three types of healthcare professionals together. Compared to participants without psychological distress, those with this problem had much more frequent visits with their family physician only or with a psychiatrist. Finally, there were no differences between participants with or without social phobia in terms of frequency of visits with healthcare professionals.

\section{Discussion}

Our results revealed that almost half of participants (47\%) with at least one mental disorder used healthcare services for MHR. This ratio is higher than that of previous studies. Usually the percentage of persons with a mental disorder seeking healthcare services hovers between 33 and 40 percent $[8,48-50]$. The proportion of individuals with mental disorders among our full sample (13.3\%) was also higher than those found in the 2002 Canadian Community Health Survey of Mental Health and Well-Being (CCHS 1.2) for Canada (9.5\%) and for all the provinces (between 6.7\% and 11.3\%) [8]. We can hypothesize that higher utilization of healthcare services for MHR (as well as prevalence of mental disorders) in our study results from the local presence of a psychiatric hospital and a large network of public and communitybased organizations involved in mental health. It may be that frequent recourse to psychologists by participants drove up the rate of service utilization. In our study, as in the province of Quebec overall, psychologists were the second most consulted professionals after family physicians $[4,8]$, while they rank third in other Canadian provinces, tied with psychiatrists and behind family physicians and social workers. The rate of Quebecers who consult psychologists is almost twice that of the Canadian average [8]. In 2008, the ratio of psychologists in Quebec was 104 per 100,000 population, as opposed to 48 per 100,000 for all of Canada [51].

The three major needs-related factors of healthcare service utilization are emotional problems, number of mental disorders and, marginally, lack of alcohol dependence. Emotional problems were the key determinant of healthcare service utilization for MHR. Such problems often involve interpersonal relationships [52]. Hence, past or recent experiences of crime and violence are a common cause of emotional problems [53,54]. A perceived inability to influence neighborhood conditions is another aspect that could explain the high prevalence of emotional problems. These findings contradict those of previous research, which found that individuals with emotional problems do not usually request healthcare services [55-57]. This difference could stem from the fact that, in our study, participants self-reported emotional problems, whereas these problems were linked to an established diagnosis such as depression or anxious disorder in other studies [58]. Various studies report that individuals with emotional problems seek professional help only when confronted with serious problems [59]. Some research found that individual behavior and beliefs (wishing to solve their problem by themselves, belief that emotional problems would go away) pose serious barriers to treatment for individuals with emotional problems [55-57]. Such attitudes tend to be more frequent among younger individuals with less education [55]. The literature, however, exposes other major obstacles to healthcare service utilization by this clientele, including cost of services, unawareness of available services, waiting times, transportation problems, bad experiences with professionals, doubts concerning the efficacy of treatment, and fear of stigmatization [22,55-57,59-61]. 
Table 4 Participants' characteristics as regards type of professional in service utilization, most prevalent mental disorders (MD) and psychological distress in past 12 months as reported at $\mathrm{T} 2(\mathrm{~N}=1,823)$

\begin{tabular}{|c|c|c|c|c|c|c|c|c|c|c|c|c|c|c|c|c|}
\hline & & \multirow{2}{*}{\multicolumn{3}{|c|}{$\begin{array}{c}\begin{array}{c}\text { Service } \\
\text { utilization }\end{array} \\
(n=467)\end{array}$}} & \multirow{2}{*}{\multicolumn{3}{|c|}{$\begin{array}{c}\begin{array}{c}\text { Major } \\
\text { depression }\end{array} \\
(n=157)\end{array}$}} & \multirow{2}{*}{\multicolumn{3}{|c|}{$\begin{array}{c}\text { Panic disorder } \\
(n=33)\end{array}$}} & \multirow{2}{*}{\multicolumn{3}{|c|}{$\begin{array}{l}\text { Social phobia } \\
\qquad(n=61)\end{array}$}} & \multirow{2}{*}{\multicolumn{3}{|c|}{$\begin{array}{c}\begin{array}{c}\text { Psychological } \\
\text { distress }\end{array} \\
(n=651)\end{array}$}} \\
\hline & & & & & & & & & & & & & & & & \\
\hline & & $\mathrm{n}$ & $\%$ & $P$ value & $\mathrm{n}$ & $\%$ & $P_{\text {value }}{ }^{1}$ & n & $\%$ & P value $^{2}$ & $\mathrm{n}$ & $\%$ & P value $^{3}$ & $\mathrm{n}$ & $\%$ & $P_{\text {value }}{ }^{4}$ \\
\hline \multirow{9}{*}{$\begin{array}{l}\text { Professionals visited in past } 12 \text { months } \\
\text { reported at T1 }\end{array}$} & Family physician & 70 & 15.0 & & 27 & 17.2 & $<.001^{*}$ & 4 & 12.1 & $.035^{* *}$ & 4 & 6.6 & $.292^{* *}$ & 41 & 6.3 & $<.001^{*}$ \\
\hline & Psychologist & 48 & 10.3 & & 16 & 10.2 & $<.001^{*}$ & 3 & 9.1 & $.054^{* *}$ & 5 & 8.2 & $.006^{*}$ & 28 & 4.3 & $.001^{*}$ \\
\hline & Psychiatrist & 36 & 7.7 & & 13 & 8.3 & $<.001^{*}$ & 1 & 3.0 & $.485^{* *}$ & 3 & 4.9 & $.117^{* *}$ & 21 & 3.2 & $.004^{*}$ \\
\hline & Other professionals & 37 & 7.9 & & 9 & 5.7 & $.001^{*}$ & 1 & 3.0 & $.495^{* *}$ & 4 & 6.6 & $.033^{* *}$ & 17 & 2.6 & $.189^{*}$ \\
\hline & Psychologist and family physician & 102 & 21.8 & & 32 & 20.4 & $<.001^{*}$ & 4 & 12.1 & $.109^{* *}$ & 8 & 13.1 & $.009^{*}$ & 56 & 8.6 & $<.001^{*}$ \\
\hline & Psychiatrist and family physician & 93 & 19.9 & & 30 & 19.1 & $<.001^{*}$ & 4 & 12.1 & $.084^{* *}$ & 6 & 9.8 & $.087^{*}$ & 52 & 8.0 & $<.001^{*}$ \\
\hline & Psychiatrist and psychologist & 69 & 14.8 & & 21 & 13.4 & $<.001^{*}$ & 3 & 9.1 & $.126^{* *}$ & 7 & 11.5 & $.001^{*}$ & 38 & 5.8 & $.001^{*}$ \\
\hline & Psychiatrist, family physician and psychologist & 116 & 24.8 & & 32 & 20.4 & $<.001^{*}$ & 4 & 12.1 & $.154^{* *}$ & 9 & 14.8 & $.006^{*}$ & 61 & 9.4 & $<.001^{*}$ \\
\hline & $\begin{array}{l}\text { Psychiatrist, family physician, psychologist and other } \\
\text { professionals }\end{array}$ & 138 & 29.6 & & 35 & 22.3 & $<.001^{*}$ & 4 & 12.1 & $.309^{* *}$ & 11 & 18.0 & $.002^{*}$ & 71 & 10.9 & $<.001^{*}$ \\
\hline
\end{tabular}

*Pearson's chi-square test; **Fisher's exact test.

${ }^{1}$ Compare to those without Major depression.

${ }^{2}$ Compare to those without Panic disorder.

${ }^{3}$ Compare to those without Social phobia.

${ }^{4}$ Compare to those without Psychological distress. 
Table 5 Participants' pattern of frequency of visits with professionals as regards most prevalent mental disorders (MD), psychological distress in past 12 months and number of MD as reported at T2 $(N=1823)$

\begin{tabular}{|c|c|c|c|c|c|c|c|c|c|c|c|c|c|c|c|c|c|c|}
\hline \multirow[b]{2}{*}{ Frequency of visits to professionals } & \multicolumn{3}{|c|}{$\begin{array}{c}\text { Major depression } \\
(n=157)\end{array}$} & \multicolumn{3}{|c|}{$\begin{array}{l}\text { Panic disorder } \\
\qquad(n=33)\end{array}$} & \multicolumn{3}{|c|}{$\begin{array}{l}\text { Social phobia } \\
\qquad(n=61)\end{array}$} & \multicolumn{3}{|c|}{$\frac{\text { Psychological distress }}{(n=651)}$} & \multicolumn{3}{|c|}{$\begin{array}{l}\text { Number of mental } \\
\text { disorders in past } 12 \\
\text { months excluding } \\
\text { dependence to } \\
\text { alcohol and drugs }\end{array}$} & \multicolumn{3}{|c|}{$\begin{array}{l}\text { Number of mental } \\
\text { disorders in past } 12 \\
\text { months including } \\
\text { dependence to } \\
\text { alcohol and drugs }\end{array}$} \\
\hline & Mean & SD & $\mathrm{P}_{\text {value }}{ }^{*}$ & Mean & SD & P value $^{2 *}$ & Mean & SD & P value $^{3 *}$ & Mean & SD & P value ${ }^{4 *}$ & Mean & SD & P value** & Mean & SD & $P$ value ${ }^{* *}$ \\
\hline Family physician & 0.9 & 3.1 & $<.001$ & 0.6 & 2.3 & .002 & 0.7 & 3.6 & .954 & 0.3 & 2.1 & .028 & 0.6 & 0.8 & $<.001$ & 0.7 & 1.0 & $<.001$ \\
\hline Psychologist & 1.8 & 9.5 & .001 & 2.2 & 9.4 & .004 & 0.9 & 3.2 & .122 & 0.5 & 3.4 & .082 & 0.6 & 1.0 & .002 & 0.7 & 1.0 & .011 \\
\hline Psychiatrist & 0.2 & 0.9 & .001 & 0.1 & 0.5 & .512 & 0.1 & 0.6 & .452 & 0.1 & 0.7 & .138 & 0.7 & 1.0 & .180 & 0.8 & 1.1 & .438 \\
\hline Other professionals & 0.8 & 4.3 & .168 & 0.1 & 0.7 & .531 & 0.8 & 3.3 & .148 & 0.6 & 6.7 & .947 & 0.5 & 0.9 & .697 & 0.6 & 1.1 & .580 \\
\hline Psychologist and family physician & 2.7 & 10.5 & $<.001$ & 2.8 & 11.6 & .023 & 1.5 & 4.8 & .258 & 0.8 & 4.4 & .054 & 0.5 & 0.8 & $<.001$ & 0.6 & 0.9 & $<.001$ \\
\hline Psychiatrist and family physician & 1.2 & 3.5 & $<.001$ & 0.7 & 2.6 & .013 & 0.8 & 3.7 & .679 & 0.4 & 2.3 & .041 & 0.6 & 0.8 & $<.001$ & 0.6 & 0.9 & $<.001$ \\
\hline Psychiatrist and psychologist & 2.0 & 9.9 & .001 & 2.3 & 9.5 & .035 & 1.0 & 3.3 & .073 & 0.6 & 3.6 & .121 & 0.6 & 0.9 & .002 & 0.6 & 1.0 & .011 \\
\hline Psychiatrist, family physician and psychologist & 3.0 & 11.0 & $<.001$ & 2.9 & 11.8 & .046 & 1.6 & 4.8 & .236 & 0.9 & 4.6 & .128 & 0.5 & 0.8 & $<.001$ & 0.6 & 0.9 & $<.001$ \\
\hline $\begin{array}{l}\text { Psychiatrist, family physician, psychologist and } \\
\text { other professionals }\end{array}$ & 3.8 & 12.5 & .001 & 3.1 & 12.0 & .107 & 2.4 & 6.3 & .143 & 1.5 & 8.3 & .163 & 0.4 & 0.8 & .028 & 0.5 & 0.9 & .010 \\
\hline
\end{tabular}

*Independent sample t-test; **ANOVA t-test.

${ }^{1}$ Compare to those without Major depression.

${ }^{2}$ Compare to those without Panic disorder.

${ }^{3}$ Compare to those without Social phobia.

${ }^{4}$ Compare to those without Psychological distress. 
The link between the number of mental disorders over the previous 12 months and healthcare service utilization for MHR was reported previously [62]. Individuals with multiple mental disorders have more reasons to pursue treatment [2]. Substance dependents are not usually heavy service users, unless they suffer also from co-occurring mental or physical disorders [63,64].

Three enabling factors influenced healthcare service utilization: personal income, control over events occurring in the neighborhood, and quality of life. The link between healthcare service utilization and higher personal income has often been reported $[11,18,65,66]$. While individuals with low income are more likely to be affected by mental disorders [49], they use significantly fewer healthcare services. This under-utilization can be explained by some variables strongly associated with a disadvantaged socio-economic status [49]. Individuals with low income and suffering from mental disorders are usually unmarried $[4,14,48,49]$ and have less education $[4,6,14,15,31,48]$ and a weaker social network [20,23,31]. Some authors note that individuals with higher education are more apt to understand their problems and to know where to find help $[6,15]$. Moreover, it is easier for them to understand their needs, and they tend to be more receptive to treatment $[13,15]$. For their part, spouses and friends can help individuals to recognize their problems and encourage them to see a professional [31,33]. Cost of services, however, severely limits access to healthcare services, even in countries, such as Canada, that have a universal public healthcare system. [22]. For example, some professional services, such as the majority of those of psychologists, are not covered by public health insurance (in Quebec and in most western countries) and are only available, therefore, to persons with the financial means to afford them or able to rely on an insurance plan to cover the cost $[16,67]$. Reimbursement policies have a positive impact on service use [29]. In a previous paper dealing with $\mathrm{T} 1$ in the same catchment area, we found that $63 \%$ of individuals who consulted a psychologist had insurance covering psychological services [33].

The link between perceived inability to influence neighborhood conditions and healthcare service utilization can be explained by the deleterious effects of social disorganization on mental health [68]. Inability to change the social environment is a major cause of stress, which can trigger emotional problems, psychological distress, anxiety and depression or lead to substance abuse [68-71]. Conversely, social cohesion in the neighbourhood increases well-being and reduces daily stressors [72]. Moreover, residential stability increases interactions between neighbours and fosters stronger social relationships [71,73]. Concerning quality of life, some studies have found that social fears both decrease quality of life and increase healthcare service utilization [74-76]. Moreover, quality of life is lower among individuals suffering from multiple mental disorders [74], who are also more likely to use services.

Only two predisposing factors impacted healthcare service utilization: female gender and legal problems in the past 12 months. Concerning gender, several studies have found much higher healthcare service utilization for MHR among females than males [6,10-12,14,16,24,48,77,78]. A possible explanation is that females suffer more frequently from anxiety disorders, mood disorders and psychological distress [79]. Compared to the other gender, males are also less aware of their mental health [80-82], have more difficulty in accepting a diagnosis of mental illness [12] and tend to avoid seeking help until there is a sharp deterioration of their condition $[6,48,78]$. Physical symptoms are the determining factor of healthcare service utilization by males [83]. Moreover, it appears that family physicians are more comfortable treating females, so that males are more commonly referred to specialists [6]. We were surprised to find that legal problems in the past 12 months could be a key determinant of healthcare service utilization for MHR. Usually, conflicts with the law create a barrier to healthcare service utilization since prison inmates often fail to get help for their mental health problems [84,85]. Previous run-ins with the law may have led some participants with mental disorders to seek help, or it could be that individuals with legal problems have agreed to receive mental healthcare services in exchange for a reduced sentence [86].

In terms of type of professionals consulted and frequency of visits in connection with mental disorders and psychological distress, the study confirmed the expected link between major depression and recourse to different professionals and a high frequency of visits [16]. This mental disorder is the one for which the help of healthcare professionals is most often sought [16]. According to the literature, individuals with major depression benefit the most from interventions based on inter-professional collaboration [87-89]. The focus on major depression in anti-stigmatization campaigns and current mental health reforms could also explain the frequent recourse to healthcare professionals [90].

There is an apparent contradiction concerning the number of professionals consulted and the frequency of visits among individuals with psychological distress, panic disorder and social phobia. Participants with psychological distress are more likely to consult all types of professionals. However, in term of frequency of visits, a family physician alone or both a family physician and psychiatrist are the only professionals on whom they call significantly more often. Curiously, psychological distress had no significant impact on frequency of visits with a psychologist. Many individuals suffering from psychological distress may thus prefer medication to long-term 
psychotherapy. Moreover, the number of psychotherapy sessions allowed by private insurance is limited [91]. The study confirmed that individuals with panic disorder frequently consult healthcare professionals [32,92]. Suicide ideation or attempts are higher among sufferers of panic disorder, which explains their frequent use of emergency departments and ambulatory services [32,92]. As observed in other studies, however, the only professional usually called upon for panic disorder was the family physician [87-89], probably because related symptoms are generally physical (hyperventilation, heart palpitation, chest pain, etc.). It is possible that individuals with panic disorder seek the services of several professionals according to the severity of their condition but use their family doctor as a regular source of healthcare. Having a regular medical care provider is a positive factor in service utilization [13]. Conversely, individuals with social phobia call on several professionals but seem reluctant to commit to a regular healthcare provider, perhaps because their condition leads them to avoid social contacts and makes them reluctant to use healthcare services regularly [92].

On a final note, a greater number of mental disorders in the past 12 months, including or excluding dependence to alcohol or drugs, did not result in frequent visits to a psychiatrist or other professional alone. According to Meadows et al. [19], individuals who consult psychiatrists also tend to see other professionals. The frequency of visits by alcohol or drug dependents was no different from that of individuals with no dependence and this could indicate a lack of integrated treatment for cooccurring disorders [93]. Mental health professionals and addiction specialists usually work in isolation from each other, and this is reflected in the treatment of cooccurring disorders $[94,95]$.

\section{Limitations}

This study presents some limitations. First, the full spectrum of mental disorders was not included in our analysis. Individuals with personality disorders or serious mental disorders such as schizophrenia are reported to be heavy service users [96-98]. Second, we did not have information about the severity of symptoms. Previous studies reported greater healthcare service utilization among individuals with more severe psychiatric symptoms $[15,64,99]$. Third, our data cannot adequately address some determinants which can be serious barriers to healthcare service utilization, such as duration, waiting times, past experiences with professionals or satisfaction of the quality of care $[22,29,61,99]$. These situational aspects are just as important as financial considerations in cases of people not using healthcare services or dropping out of care [61]. Fourth, certain variables, such as homelessness, availability of private insurance and access to a family physician, that could influence service utilization for MHR, were not measured. Finally, the results could reflect the characteristics of the population of the catchment area and may not be generally applicable to other areas or populations.

\section{Conclusion}

This study was innovative in that it looked specifically at healthcare service utilization by individuals with mental disorders, while previous studies had put greater emphasis on the general population. Moreover, this study is of interest in that it included several variables, such as neighbourhood characteristics and legal problems, which are not usually considered. To our knowledge, no other research has analyzed healthcare service utilization with a set of such comprehensive variables using Andersen's behavioural model.

The results show that emotional problems are the chief determinant of healthcare service utilization for MHR among individuals with mental disorders. A key issue is to provide access to services for individuals suffering from emotional problems, which are often the result of interpersonal conflicts. Males are especially loath to speak of their emotional problems and to use healthcare services until confronted with a severe deterioration of their condition. Strategies to be considered include promoting help phone lines, crisis centers, bibliotherapy, internet outreach and self-help groups. This study also broke new ground by uncovering a link between legal problems in the past 12 months and healthcare service utilization among individuals with mental disorders. Problems with the law are usually considered a barrier to healthcare service utilization, although they may induce some individuals with mental disorders to seek help. Moreover, the study emphasizes the need to improve neighbourhood conditions to prevent mental disorders among poorer populations, and to increase outreach activities aimed at these groups, where there is a higher prevalence of mental disorders, psychological distress or emotional problems. Finally, this study contributes to the development of knowledge concerning frequency of visits and number of professionals consulted in connection with mental disorders and psychological disorders. Based on our analyses, major depression was the only diagnosis showing a correlation between frequency of visits and number of professionals consulted. Concerning social phobia, panic disorder and psychological distress, more frequent visits with professionals seem to have no bearing on the number of professionals consulted. Priority could be given to initiatives relying on inter-professional collaboration to increase the ability of healthcare services to take care of individuals suffering from social phobia, panic disorder and psychological distress. Better training of family physicians 
in mental health, use of psychiatric consultants, internet outreach, and free access to psychological services would be among the measures to be prioritized to increase integration and capacity of services to treat individuals affected by mental disorders or psychological distress and improve access to mental healthcare services.

\section{Competing interests}

The authors declare that they have no competing interests.

\section{Authors' contributions}

JC designed the epidemiological catchment area study. MJF, GG and JMB designed the specific research. JMB performed the statistical analyses with the help of JC. MJF and GG wrote the article. All authors have read, revised and approved the final manuscript.

\section{Acknowledgements}

The study was funded by the Canadian Institute of Health Research (CTP-79839). We would like to thank this grant agency and all individuals who participated in the research.

Received: 14 November 2013 Accepted: 25 March 2014

Published: 8 April 2014

\section{References}

1. Kessler RC, Berglund P, Demler O, Jin R, Koretz D, Merikangas KR, Rush AJ, Walters EE, Wang P, Replication NCS: The epidemiology of major depressive disorder: results from the national comorbidity survey replication (NCS-R). JAMA 2003, 289(23):3095-3105.

2. Kessler RC, Zhao S, Katz SJ, Kouzis AC, Frank RG, Edlund M, Leaf P: Past-year use of outpatient services for psychiatric problems in the national comorbidity survey. Am J Psychiatry 1999, 156(1):115-123.

3. Mojtabai R, Olfson M, Mechanic D: Perceived need and help-seeking in adults with mood, anxiety, or substance use disorders. Arch Gen Psychiatry 2002, 59(1):77-84.

4. Vasiliadis HM, Lesage A, Adair C, Boyer R: Service use for mental health raisons: cross-provincial differences in rates, determinants, and equity of access. Can J Psychiatry 2005, 50(10):614-619.

5. Wang PS, Berglund P, Olfson M, Pincus HA, Wells KB, Kessler RC: Failure and delay in initial treatment contact after first onset of mental disorders in the national comorbidity survey replication. Arch Gen Psychiatry 2005, 62(6):603-613.

6. Wang PS, Lane M, Olfson M, Pincus HA, Wells KB, Kessler RC: Twelve-month use of mental health services in the United States. Arch Gen Psychiatry 2005, 62(6):629-640.

7. Wittchen HU, Jacobi F: Size and burden of mental disorders in Europe- a critical review and appraisal of 27 studies. Eur Neuropsychopharmacol 2005, 256(3):187-196.

8. Lesage A, Vasiliadis H-M, Gagné M-A, Dudgeon S, Kasman N, Hay C: Prevalence of mental illness and related service utilization in Canada: an analysis of the Canadian community health survey. Mississauga, Ontario: Canadian Collaborative Mental Health Initiative; 2006.

9. Andersen RM: Revisiting the behavioral model and access to medical care: does it matter? J Health Soc Behav 1995, 36(1):1-10

10. Carr VJ, Johnston PJ, Lewin TJ, Rajkumar S, Carter GL, Issakidis C: Patterns of service use among persons with schizophrenia and other psychotic disorders. Psychiatr Serv 2003, 54(2):226-235.

11. Narrow WE, Regier DA, Norquist G, Rae DS, Kennedy C, Arons B: Mental health service use by Americans with severe mental illnesses. SoC Psychiatry Psychiatr Epidemiol 2000, 35(4):147-155.

12. Uebelacker LA, Wang PS, Berglund P, Kessler RC: Clinical differences among patients treated for mental health problems in general medical and specialty mental health settings in the national Comoribidity survey replication (NCS-R). Gen Hosp Psychiatry 2006, 28(5):387-395.

13. Leaf PJ, Livingston MM, Tischler GL, Weissman MM, Holzer CE, Myers JK: Contact with health professionals for the treatment of psychiatric and emotional problems. Med Care 1985, 23(12):1322-1337.

14. Bebbington P, Meltzer $H$, Brugha TS, Farrell M, Jenkins R, Ceresa C, Lewis $G$ : Unequal access and unmet need: neurotic disorders and the use of primary care services. Psychol Med 2000, 30(6):1359-1367.
15. Parslow RA, Jorm AF: Who uses mental health services in Australia? An analysis of data from the national survey of mental health and wellbeing. Aust N Z J Psychiatry 2000, 34(6):997-1008.

16. Vasiliadis HM, Lesage A, Adair C, Wang PS, Kessler RC: Do Canada and the United States differ in prevalence of depression and utilization of services? Psychiatr Serv 2007, 58(1):63-71.

17. Alegria M, Bijl RV, Lin E, Walters EE, Kessler RC: Income differences in persons seeking outpatient treatment for mental disorders. Arch Gen Psychiatry 2000, 57(4):383-391.

18. Wang PS, Berglund P, Kessler RC: Recent care of common mental disorders in the United States: prevalence and conformance with evidence-based recommendations. J Gen Intern Med 2000, 15(5):284-292.

19. Meadows $G$, Singh B, Burgess P, Bobevski I: Psychiatry and the need for mental health care in Australia: findings from the national survey of mental health and wellbeing. Aust N Z J Psychiatry 2002, 36(2):210-216.

20. Albert M, Becker T, McCrone P, Thornicroft G: Social networks and mental health service utilisation: a literature review. Int J Soc Psychiatry 1998, 44(4):248-266.

21. Pescosolido BA, Wright ER, Alegria M, Vera M: Social networks and patterns of use among the poor with mental health problems in Puerto Rico. Med Care 1998, 36(7):1057-1072.

22. Chartier-Otis M, Perreault M, Bélanger C: Determinants of barriers to treatment for anxiety disorders. Psychiatr Q 2010, 81(2):127-138.

23. Lemming MR, Calsyn RJ: Utility of the behavioral model in predicting service utilization by individuals suffering from severe mental illness and homelessness. Community Ment Health J 2004, 40(4):347-364.

24. Lefebvre J, Lesage A, Cyr M, Toupin J, Fournier L: Factors related to utilization of services for mental health reasons in Montreal, Canada. Soc Psychiatry Psychiatr Epidemiol 1998, 33(6):291-298.

25. Lin E, Goering P, Offord DR, Campbell D, Boyle MH: The use of mental health services in Ontario: epidemiologic findings. Can J Psychiatry 1996, 41:572-577.

26. Dhingra SS, Zack M, Strine T, Pearson WS, Balluz L: Determining prevalence and correlates of psychiatric treatment with Andersen's behavorial model of health services use. Psychiatr Serv 2010, 61(5):514-528.

27. Meadows G, Gielewski H, Falconer B, Kelly H, Joubert L, Clarke M: The pattern-of-care model: a tool for planning community mental health services. Psychiatr Serv 1997, 48(2):218-223.

28. Wang PS, Demler O, Olfson M, Pincus HA, Wells KB, Kessler RC: Changing profiles of service sectors used for mental health care in the United States. Am J Psychiatry 2006, 163(7):1187-1198.

29. Dezetter A, Briffault $X$, Alonso J, Angermeyer MC, Bruffaerts R, de Girolamo G, De Graaf R, Haro JM, Konig HH, Kovess-Masfety V: Factors associated with use of psychiatrists and nonpsychiatrist providers by ESEMeD respondents in six European countries. Psychiatr Serv 2011, 62(2):143-151.

30. Dezetter A, Briffault X, Bruffaerts R, De Graaf R, Alonso J, König HH, Haro JM, De Girolamo G, Vilagut G, Kovess-Masféty V: Use of general practitioners versus mental health professionals in six Europeans countries: the decisive role of the organization of mental health-care systems. Soc Psychiatry Psychiatr Epidemiol 2013, 48:137-149.

31. Howard KI, Cornille TA, Lyons JS, Vessey JT, Lueger RJ, Saunders SM: Patterns of mental health service utilization. Arch Gen Psychiatry 1996, 53(8):696-703.

32. Katerndahl DA, Realini JP: Use of health care services by persons with panic symptoms. Psychiatr Serv 1997, 48(8):1027-1032.

33. Fleury MJ, Grenier G, Bamvita JM, Perreault M, Caron J: Determinants of the utilization of diversified types of professionals for mental health reasons in a Montreal (Canadian) catchment area. Glob J Health Sci 2012, 4(3):13-29.

34. Fleury MJ, Grenier G, Bamvita JM, Tremblay J: Factors associated with needs of users with severe mental disorders. Psychiatr Q 2013, 84(3):363-379.

35. Eaton WW, Anthony JC, Tepper S, Dryman A: Psychopathology and attrition in the epidemiologic catchment area surveys. Am J Epidemiol 1992, 135(9):1051-1059.

36. De Graaf R, Bijl RV, Smit F, Ravelli A, Vollebergh WA: Psychiatric and sociodemographic predictors of attrition in a longitudinal study: the Netherlands mental health survey and incidence study (NEMESIS). Am J Epidemiol 2000, 152(11):1039-1047.

37. Bucholz KK, Shayka JJ, Marion SL, Lewis CE, Pribor EF, Rubio DM: Is a history of alcohol problems or of psychiatric disorder associated with attrition at 11-year follow-up? Ann Epidemiol 1996, 6(3):228-234. 
38. Caron J, Fleury MJ, Perreault M, Crocker A, Tremblay J, Tousignant M, Kestens Y, Cargo M, Daniel M: Prevalence of psychological distress and mental disorders, and use of mental health services in the epidemiological catchment area of Montreal South-West. BMC Psychiatry 2012, 12:183.

39. Statistics Canada: Canadian community Health Survey: mental health and well-being. The daily 2003. 2003

40. Baker F, Intagliata J: Quality of life in the evaluation of community support systems. Eval Prorgram Plann 1982, 5(1):69-79.

41. Perkins DD, Long DA: Neighborhoud sense of community and social capital: a multi-level analysis. In Psychological Sense of Community: Research, Applications and Implications. Edited by Fisher AT, Sonn CC, Bishop BJ. New York: Plenum; 2002:291-318.

42. Coulton C, Theodos B, Turner MA: Residential mobility and neighborhood change: real neighborhoods under the microscope. Cityscape 2012, 14(3):55-90

43. Saegert S, Winke G: Crime, social capital, and community participation. Am J Community Psychol 2004, 34(3-4):219-233.

44. Nario-Redmond M, Coulton C: Measuring Resident Perceptions of Neighborhood Conditions: Survey Methodology. Urban Poverty Center. 2000

45. Cutrona CE: Behavioral manifestation of social support: a micro-analytic study. J Pers Soc Psychol 1989, 51(1):201-208.

46. Kay SR, Wolkenfied F, Murrill LM: Profiles of aggression among psychiatrist patients: I. nature and prevalence. J Nerv Ment Dis 1988, 176(9):539-546.

47. Kessler RC, Barker PR, Colpe LJ, Epstein JF, Groerer JC, Hiripi E, Howes MJ, Normand S-L, Mandercheid RW, Walters EE, Zaslavsky AM: Screening for serious mental illness in the general population. Arch Gen Psychiatry 2003, 60(2):184-189.

48. Andrews $\mathrm{G}$, Issakidis $\mathrm{C}$, Carter $\mathrm{G}$ : Shortfall in mental health service utilisation. Br J Psychiatry 2001, 179:417-425.

49. Kessler RC, Chiu WT, Demler O, Walters EE: Prevalence, severity, and comorbidity of 12-month DSM-IV disorders in the national comorbidity survey replication. Arch Gen Psychiatry 2005, 62(6):617-627.

50. Codony M, Alonso J, Almansa J, Bernert S, de Girolamo G, de Graaf R, Haro JM, Kovess V, Vilagut G, Kessler RC: Perceived need for mental health care and service use among adults in Western Europe: results of the ESEMeD project. Psychiatr Serv 2009, 60(8):1051-1058.

51. ClHI: Health Care in Canada. Ottawa, Ontario: Canadian Institute for Health Information; 2008.

52. Whisman MA, Uebelacker LA: Impairment and distress associated with relationship discord in a national sample of married or cohabiting adults. J FamPsychol 2006, 20(3):369-377.

53. Brand B: Trauma and women. Psychiatr Clin North Am 2003, 26(3):759-579.

54. Amstadter A, Zinzow HM, McCauley JL, Strachan M, Ruggerio KJ, Resnick HS, Kilpatrick DG: Prevalence and correlates of service utilization and help seeking in a national college sample of female rape victims. J Anxiety Disord 2010, 24(8):900-902.

55. Saldivia S, Vicente B, Kohn R, Rioseco P, Torres S: Use of mental health services in Chile. Psychiatr Serv 2004, 55(1):71-76.

56. Wells JE, Robins LN, Bushnell JA, Jarosz D, Oakley-Browne MA: Perceived barriers to care in St. Louis (USA) and Christchurch (NZ): reasons for not seeking professional help for psychological distress. Soc Psychiatry Psychiatr Epidemiol 1994, 29(4):155-164.

57. Sareen J, Jagdeo A, Cox BJ, Clara I, Ten Have M, Belik S-L, De Graaf R, Stein MB: Perceived barriers to mental health service utilization in the United States, Ontario, and the Netherlands. Psychiat Serv 2007, 58(3):357-364

58. den Boer PC, Wiersma D, Van den Bosch RJ: Why is self-help neglected in the treatment of emotional disorders? a meta-analysis. Psychol Med 2004, 34(6):959-971.

59. ten Have $M$, de Graaf $R$, Ormel J, Vilagut $G$, Kovess V, Alonso J, Investigators ESM: Are attitudes towards mental health help-seeking associated with service use? results from the European study of epidemiology of mental disorders. Soc Psychiatry Psychiatr Epidemio 2010, 45(2):153-163.

60. Fossey E, Harvey C, Mokhtari MR, Meadows GN: Self-rated assessment of needs for mental health care: a qualitative analysis. Community Ment Health J 2012, 48(4):407-419.

61. Kessler RC, Berglund PA, Bruce ML, Koch JR, Laska EM, Leaf PJ, Mandercheid RW, Rosenheck RA, Walters EE, Wang PS: The prevalence and correlates of untreated serious mental illness. Health Serv Res 2001, 36(6):987-1007.
62. Andrews G, Slade T, Issakidis C: Deconstructing current comorbidty: data from the Australian national survey of mental health and well-being. B J Psychiatry 2002, 181:306-314.

63. Bonin J-P, Fournier L, Blais R: Predictors of mental health service utilization by people using resources for homeless people in Canada. Psychiatr Serv 2007, 58(7):936-941.

64. Tempier R, Meadows GN, Vasiliadis HM, Mosier KE, Lesage A, Stiller A, Graham A, Lepnurm M: Mental disorders and mental health care in Canada and Australia: comparative epidemiological findings. Soc Psychiatry Psychiatr Epidemiol 2009, 44(1):63-72.

65. Olfson M, Marcus SC, Druss B, Pincus HA: National trends in the use of outpatient psychotherapy. Am J Psychiatry 2002, 159(11):1914-1920.

66. Young JG, Parker VA, Charns MP: Provider integration and local market conditions: a contingency theory perspective. Health Care Manage Rev 2001, 26(2):73-79

67. Wells KB, Manning WG, Duan N, Newhouse JP, Ware JEJ: Sociodemographic factors and the use of outpatient mental health services. Med Care 1986, 24(1):75-85.

68. Galea S, Ahern J, Rudenstine S, Wallace Z, Vlahow D: Urban built environment and depression: a multilevel analysis. J Epidemiol Comnmunity Health 2005, 59(10):822-827.

69. De Graaf R, Bijl RV, Ten Have M, Beekman AT, Volllebergh WA: Pathways to comorbidity: the transition of pure mood, anxiety and substance use disorders into comorbid conditions in a longitudinal population-based study. Journal Affect Disord 2004, 82(3):461-467.

70. Latkin CA, Curry AD: Stressful neighborhoods and depression: a prospective study of the impact of neighborhood disorder. J Health SoC Behav 2003, 44(1):34-44.

71. Stockdale SE, Wells KB, Tang L, Belin TR, Zhang L, Sherbroune CD: The importance of social context: neighborhood stressors, stress-buffering mechanisms, and alcohol, drug, and mental health disorders. Soc Sci Med 2007, 65(9):1867-1881.

72. Robinette JW, Charles ST, Mogle JA, Almeida DM: Neighborhood cohesion and daily well-being: results from a diary study. Soc Sci Med 2013, 96:174-182.

73. Sampson RJ, Raudenbush SW, Earls F: Neighborhoods and violent crime: a multilevel study of collective efficacy. Science 1997, 277(5328):918-924.

74. Acarturk C, de Graaf R, van Straten A, Have MT, Cuijpers P: Social phobia and number of social fears, and their association with comorbidity, health-related quality of life and help seeking: a population-based study. Soc Psychiatry Psychiatr Epidemiol 2008, 43(4):273-279.

75. Safren SA, Heimberg RG, Brown EJ, Holle C: Quality of life in social phobia. Depress and Anxiety 1996, 4(3):126-133.

76. Stein MB, Torgrud LJ, Walker JR: Social phobia symptoms, subtypes, and severity: findings from a community survey. Arch Gen Psychiatry 2000, 57(11):1046-1052.

77. Shapiro S, Skinner EA, Kessler LG, Von Korff M, German PS, Tischler GL, Leaf PJ, Benham L, Cottler L, Regier DA: Utilization of health and mental health services: three epidemiologic catchment area sites. Arch Gen Psychiatry 1984, 41(10):971-978.

78. Putkonen $\mathrm{H}$, Weizman-Henelius $\mathrm{G}$, Lindberg N, Romano T, HäkkänenNyholm H: Gender differences in homicide offenders' criminal career, substance abuse and mental health care: a nationwide register-based study of Finnish homicide offender 1995-2004. Crim Behav Ment Health 2010, 21(1):51-62.

79. Koopmans GT, Lamers LM: Gender and health care utilization: the role of mental distress and help-seeking propensity. Soc Sci Med 2007, 64(6):1216-1230.

80. Deen TL, Bridges AJ: Depression literacy: rates and relation to perceived need and mental health service utlization in a rural American sample. Rural Remote Health 2011, 11:1830. Online.

81. Wang J, Adair C, Fick G, Lai D, Evans B, Perry BW, Jorm BW, Addington D: Depression literacy in Alberta: findings form a general population sample. Can J Psychiatry 2007, 52(7):442-449.

82. Thompson A, Hunt C, Issakidis C: Why wait? Reasons for delay and prompts to seek help for mental health problems in an Australian clinical sample. Soc Psychiatry Psychiatr Epidemiol 2004, 39(10):810-817.

83. Moller-Leimkuhler AM: Barriers to help-seeking by men: a review of sociocultural and clinical literature with particular reference to depression. J Affect Disord 2002, 71(1-3):1-9. 
84. Weisstub DN, Arboleda-Florez J: Canadian mental health rights in an international perspective. Sante Ment Que 2006, 31(1):19-46.

85. Frappier A, Vigneault $L$, Paquet S: Mentally ill and criminalized: testimony of a dual marginalization. Sante Ment Que 2009, 34(2):21-30.

86. CIHI: Mental health, delinquency and criminal acitvity. Ottawa: Canadian Institute for Health Information; 2008.

87. Peveler R: Befriending can lead to remission in women with chronic depression. West J Med 1999, 171(4):241.

88. Peveler R, George C, Kinmonth AL, Campbell M, Thompson C: Effect of antidepressant drug counselling and information leaflets on adherence to drug treatment in primary care: randomised controlled trial. Bmj 1999, 319(7210):612-615.

89. Swindle RW, Rao JK, Helmy A, Plue L, Zhou XH, Eckert GJ, Weinberger M: Integrating clinical nurse specialists into the treatment of primary care patients with depression. Int J Psychiatry Med 2003, 33(1):17-37.

90. MHCC: Changing directions. changing lives: the mental health strategy for Canada. Calgary, Alberta: Mental Health Commission of Canada; 2012.

91. Fleury MJ, Imboua A, Aube D, Farand L: Collaboration between general practitioners (GPs) and mental healthcare professionals within the context of reforms in Quebec. Ment Health Fam Med 2012, 9(2):77-90.

92. Goodwin R, Andersen RM: Use of the behavioral model of health care use to identify correlates of use of treatment for panic attacks in the community. Soc Psychiatry Psychiatr Epidemiol 2002, 37(5):212-219.

93. Drake RE, Mueser KT, Brunette MF, McHugo GJ: A review of treatments for people with severe mental illnesses and co-occurring substance use disorders. Psychiatr Rehabil J 2004, 27(4):360-374.

94. Horsfall J, Cleary M, Hunt GE, Walter G: Psychosocial treatments for people with co-occurring severe mental illnesses and substance use disorders (dual diagnosis): a review of empirical evidence. Harv Rev Psychiatry 2009, 17(1):24-34.

95. Donald M, Dower J, Kavanagh D: Integrated versus non-integrated management and care for clients with co-occurring mental health and substance use disorders: a qualitative systematic review of randomised controlled trials. Soc Sci Med 2004, 60(6):1371-1783.

96. Kent S, Yellowlees P: Psychiatric and social reasons for frequent rehospitalization. Hosp Community Psychiatry 1994, 45(4):347-350.

97. Kent S, Fogarty M, Yellowlees P: A review of studies of heavy users of psychiatric services. Psychiatr Serv 1995, 46(12):1247-1253.

98. Chaput YJ, Lebel M-J: Demographic and clinical profiles of patients who make multiple visits to psychiatric emergency services. Psychiatr Serv 2007, 58(3):335-341.

99. Wang PS, Aguilar-Gaxiola S, Alonso J, Angermeyer MC, Borges G, Bromet EJ, Bruffaerts R, de Girolama G, de Graff R, Gureje O, Haro JM, Karm EG, Kessler RC, Kovess V, Lane MC, Lee S, Levinson D, Ono Y, Petukhova M, Posada-Villa J, Seedat S, Wells JE: Use of mental health services for anxiety, mood, and substance disorders in 17 countries in the WHO world mental health surveys. Lancet 2007, 370(9590):841-850.

doi:10.1186/1472-6963-14-161

Cite this article as: Fleury et al: Determinants and patterns of service utilization and recourse to professionals for mental health reasons. $B M C$ Health Services Research 2014 14:161.

\section{Submit your next manuscript to BioMed Central and take full advantage of:}

- Convenient online submission

- Thorough peer review

- No space constraints or color figure charges

- Immediate publication on acceptance

- Inclusion in PubMed, CAS, Scopus and Google Scholar

- Research which is freely available for redistribution 